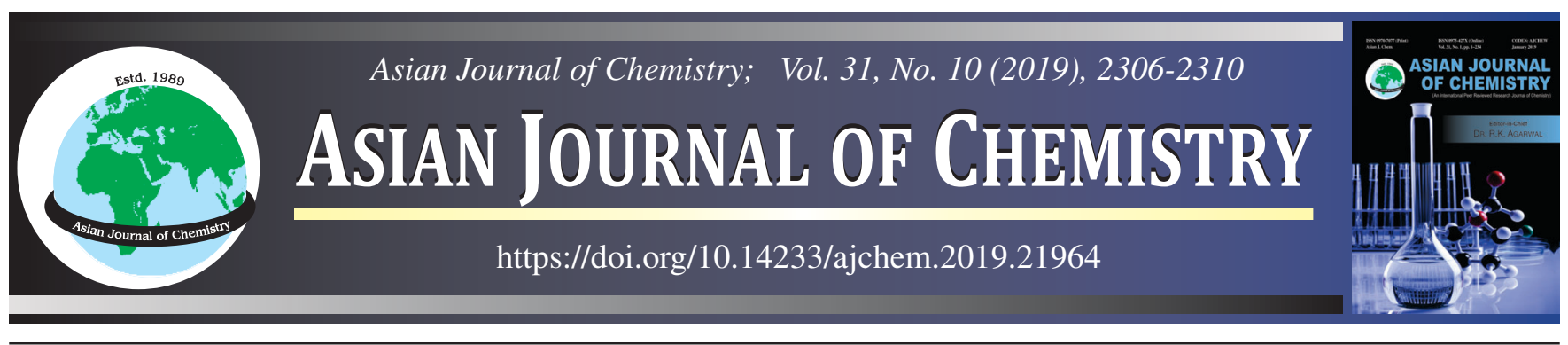

\title{
Gomphrena serrata Leaf Extract as Corrosion Inhibitor and Reductant for the Synthesis of Copper Nanoparticles
}

\section{S. Vidhya*, A. LeEma Rose and F. JANeEta Priya}

Department of Chemistry, Holy Cross College (Autonomous), Tiruchirappalli-620002, India

*Corresponding author: E-mail: vidhyachem@hcctrichy.ac.in

Received: 27 January 2019;

Accepted: 31 May 2019;

Published online: 30 August 2019;

AJC-19541

\begin{abstract}
Adapting eco-friendly methodologies is the need of the hour in the every field of research. In the present work an investigation on Gomphrena serrata leaves was evaluated as a corrosion inhibitor for the mild steel in $\mathrm{HCl}$ medium and as a reductant. The G. serrata as an efficient inhibitor it obeys Langmuir adsorption isotherm and served as anodic type inhibitor. The impedance study confirms the formation of thin film on the metal surface through its $C_{\mathrm{dl}}$ and $\mathrm{R}_{\mathrm{ct}}$ values. The copper nanoparticles and their derivatives have been used as a medicine to prevent infection, leg ulcers etc. Gomphrena serrata leaves have good medicinal values, to enhance its medicinal properties it was mediated for the synthesis of copper nanoparticles. The CuNPs formation was confirmed by SPR bands at $345 \mathrm{~nm}$ by microwave method and at $341 \mathrm{~nm}$ by thermostat method. The functional groups present in the G. serrata also present in the FTIR spectra of CuNPs and it confirms the $G$. serrata was used as a reducing as well as a capping agent.
\end{abstract}

Keywords: G. serrata, Corrosion inhibitor, CuNPs.

\section{INTRODUCTION}

Gomphrena serrata leaves belongs to the Amaranthaceae family and recognized as medicine for bronchial asthma, diarrhea, hay fever, pains, tonic, carminative, diabetes, dermatitis and piles [1,2]. Plants are the gracious gift, as it has various attributes towards the human life and the phyto constituents present may be the responsible for the healing property. Based on the attributes and to adopt the green principle of "Source Reduction-substitution of raw materials" the plants are accepted as green inhibitors and green reducing agents. Mild steel is a significant metal, which has diverse application in industries and its deterioration causes a major economic loss. Using corrosion inhibitors the deterioration can be prevented and protected [3-5]. Though the synthetic organic inhibitors show high inhibitive effect towards the corrosion, it affects the environment during its process [6]. Green inhibitors are accepted by the researchers as they are ecologically acceptable, environmental friendly, low-cost and non-toxic [7-9]. Copper nanoparticles has significant role in the medicinal field such as wound dressings and biocidal effects [10]. The nanoparticles have a greater surface area per weight than larger particles, which causes them to be more reactive and enhance the therapeutic effectiveness to targeted drug delivery. Here the present work was to investigate the Gomphrena serrata leaves as a corrosion inhibitor for the mild steel in $0.5 \mathrm{M} \mathrm{HCl}$ medium and as a reducing and a capping agent for the synthesis of copper nanoparticles.

\section{EXPERIMENTAL}

Preparation and phytochemical analysis of leaf extract: Fresh leaves of $G$. serrata were collected from in and around Tiruchirappalli. The fresh leaves were dried under shade and extraction of the crude sample was carried out using cold percolation method [11]. The active phyto compounds present in the leaf extract was analyzed using preliminary phytochemical standard procedures [12].

Determination of corrosion rate by weight loss measurements: The mild steel coupons $(0.026 \% \mathrm{~S}, 0.06 \% \mathrm{P}, 0.4 \%$ $\mathrm{Mn}$ and $0.1 \% \mathrm{C}$ and rest $\mathrm{Fe}$ ) were immersed in beaker containing $100 \mathrm{~mL}$ acid solution without and with different concentrations of $G$. serrata leaves extract using hooks. The tested specimen was cleaned and weighed under ASTM G-81 procedure. By varying the concentration, time and temperature

This is an open access journal, and articles are distributed under the terms of the Attribution 4.0 International (CC BY 4.0) License. This license lets others distribute, remix, tweak, and build upon your work, even commercially, as long as they credit the author for the original creation. You must give appropriate credit, provide a link to the license, and indicate if changes were made. 
the studies were carry out and the \% inhibition efficiency and the corrosion rate was calculated using the formulae:

$$
\text { Corrosion rate }(\mathrm{mpy})=\frac{87.6 \times \mathrm{W}}{\mathrm{A} \times \mathrm{T} \times \mathrm{D}}
$$

Electrochemical measurements: The charge transfer resistance $\left(\mathrm{R}_{\mathrm{ct}}\right)$ and capacitance double layer $\left(\mathrm{C}_{\mathrm{dl}}\right)$ were calculated using AC signals of amplitude $10 \mathrm{mV}$ peak-to-peaks at the open circuit potential in the frequency range of $10 \mathrm{MHz}$ to $1 \mathrm{~Hz}$ through electrochemical impedance spectroscopy using Electrochemical System Model Vertex 100 mA.D with IVIUM software. The $\mathrm{I}_{\text {corr }}$ and $\mathrm{E}_{\text {corr }}$ values were calculated using potentiodynamic polarization with scan rate of $5 \mathrm{mV} \mathrm{s}^{-1}$. The polarization resistance $\left(R_{p}\right)$ was calculated from the linear polarization measurement.

Morphological investigation: The surface morphology of the mild steel specimen immersed in the presence and absence of the G. serrata were studied by FTIR using Perkin-Elmer 1600 FTIR spectrophotometer with a resolving power of 4 $\mathrm{cm}^{-1}$ and SEM using F E I Quanta FEG 200-High resolution scanning electron microscope (SRM University, Kattankulathur).

Green synthesis of copper nanoparticles: The pilot experiments were carried out using $1 \mathrm{~mL}$ of $1 \mathrm{mM}$ copper sulphate with $1 \mathrm{~mL}$ of $G$. serrata extract and kept in a microwave oven and duplicate is kept in thermostat at room temperature for $1 \mathrm{~h}$. The change in colour confirms the presence of copper nanoparticles.

Characterization of copper nanoparticles: The synthesized copper nanoparticles was monitored by SPR band of UVvisible spectroscopy and the active biomolecules present in the $G$. serrata were responsible for the stabilization of copper nanoparticles was confimed by FTIR studies.

\section{RESULTS AND DISCUSSION}

The presence of alkaloid, tannin, flavonoid, proteins, steroids, carbohydrates, poly phenol, glycoside, terpenoids and triterpenoids were confirmed by the preliminary qualitative analysis. These active biomolecules are responsible for the special properties.

Weight loss measurements: The weight loss method reveals that the corrosion rate decreases and the inhibition efficiency increases with increasing $G$. serrata concentration. The corrosion rate decreases due to the adsorption and coverage of the inhibitor molecule on the metal surface. The maximum inhibition efficiency was found to be $86.9 \%$ for $700 \mathrm{ppm}$ (Fig. 1). As the corrosion rate is temperature dependent the studies show that the corrosion rate increases with increasing the temperature because of the desorption of molecules from the metal surface (Table-1).

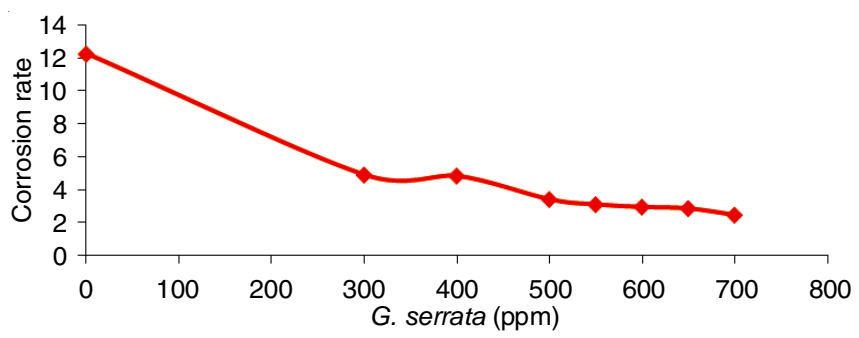

Fig. 1. Corrosion rate of $G$. serrata at different concentration
TABLE-1

EFFECT OF TEMPERATURE ON THE CORROSION RATE OF G. serrata AT 700 ppm

\begin{tabular}{cccc}
\hline \multirow{2}{*}{ Temp. (K) } & \multicolumn{2}{c}{ Corrosion rate } & \multirow{2}{*}{ IE (\%) } \\
\cline { 2 - 3 } & Blank & G. serrata & \\
\hline 303 & 12.2334 & 2.6700 & 86.90 \\
313 & 21.4000 & 6.1000 & 76.80 \\
323 & 31.7200 & 15.2999 & 57.21 \\
333 & 50.2600 & 36.4200 & 29.62 \\
\hline
\end{tabular}

Thermodyamic parameters: The temperature dependence of corrosion rate can be evaluated by change in enthalpy $\left(\Delta \mathrm{H}^{*}\right)$ from transition state equation and energy of activation $\left(\mathrm{E}_{\mathrm{a}}\right)$ from Arrhenius equation [13,14].

From the Arrhenius plot (Fig. 2a) the linear regression of blank and inhibitor are close to unity and the energy of activation is calculated from the graphical method and reveals that the $\mathrm{E}_{\mathrm{a}}$ value is higher in the presence of G. serrata $(83.88 \mathrm{~kJ}$ $\mathrm{mol}^{-1}$ ) suggest the formation of thin film on the surface of the metal surface favours the physical adsorption [15]. From the straight line of transition plot slope (Fig. 2b) and the intercept, the enthalpy is calculated. The positive value of $\Delta \mathrm{H}^{*}(82.3518$ $\mathrm{kJ} \mathrm{mol}^{-1}$ ) reflects the endothermic nature which means the metal dissolution is difficult in the presence of G. serrata [16].

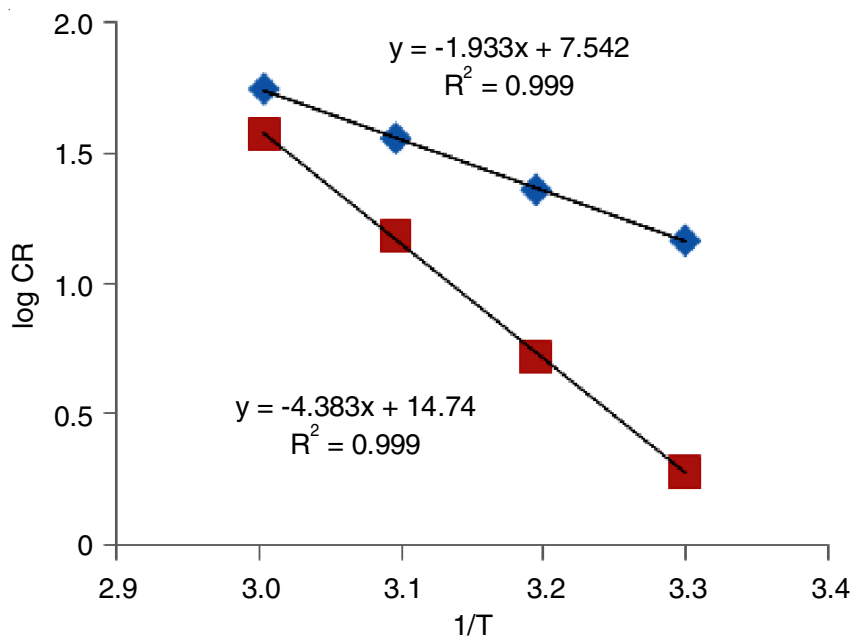

Fig. 2a. Arrhenius plot

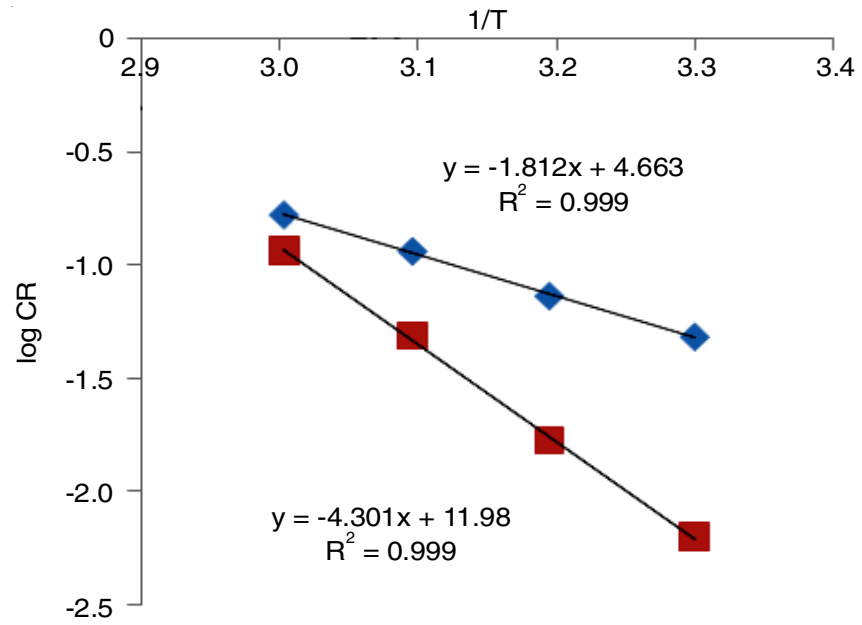

Fig. 2b. Transtition state plot 
Langmuir adsorption isotherm: This adsorption isotherm gives the information about the interaction of G. serrata and the metal surface. The regression value of the straight line is nearly one it indicates the strong adherence of $G$. serrata on the metal surface.

The $\Delta \mathrm{G}_{\text {ads }}^{\circ}$ is calculated from the eqn. 2 and the $\mathrm{K}_{\text {ads }}$ values can be calculated from the intercept lines.

$$
\Delta \mathrm{G}^{\circ}=-\mathrm{RT} \ln \left(55.5 \mathrm{~K}_{\mathrm{ads}}\right)
$$

where 55.5 is the water concentration of the solution in $\mathrm{mL} / \mathrm{L}$. The calculated $\Delta \mathrm{G}_{\text {ads }}^{\circ}$ is $-13.717 \mathrm{~kJ} \mathrm{~mol}^{-1}$ and its negative value implies that the adsorption is spontaneous in nature that means the G. serrata bio active molecules are readily adsorbed on the metal surface and retard the surface from corrosion. The calculated $\Delta \mathrm{G}_{\text {ads }}^{\circ}$ value is $-13.717 \mathrm{~kJ} \mathrm{~mol}^{-1}$ indicates the electrostatic attraction between the $G$. serrata molecules and the metal surface [17].

Impedance spectroscopy: The EIS parameter was calculated from the impedance behaviour of metal surface with and without $G$. serrata and the results are tabulated in Table-2.

\begin{tabular}{cccc} 
TABLE-2 \\
ELECTROCHEMICAL IMPEDANCE \\
PARAMETERS OF G. serrata \\
\hline System & $\mathrm{R}_{\mathrm{s}}(\Omega)$ & $\mathrm{R}_{\mathrm{ct}}\left(\Omega \mathrm{cm}^{2}\right)$ & $\mathrm{C}_{\mathrm{dl}}\left(\mathrm{F} \mathrm{cm}^{-2}\right)$ \\
\hline Blank & 23 & 117 & $1.455 \times 10^{-4}$ \\
Inhibitor & 73 & 493 & $1.180 \times 10^{-4}$ \\
\hline
\end{tabular}

The $\mathrm{R}_{\mathrm{ct}}$ value increases from $117 \Omega \mathrm{cm}^{2}$ (blank) to $493 \Omega$ $\mathrm{cm}^{2}$ on addition of $700 \mathrm{ppm}$ of inhibitor. The $\mathrm{C}_{\mathrm{dl}}$ value decreases from $1.455 \times 10^{-4} \mathrm{~F} \mathrm{~cm}^{-2}$ (blank) to $1.18 \times 10^{-4} \mathrm{~F} \mathrm{~cm}^{-2}$ ) (Fig. $3)$. The decrease in the capacitance $\left(\mathrm{C}_{\mathrm{dl}}\right)$ on the addition of inhibitor may increase the thickness of the double layer, which increases in local dielectric constant [18].

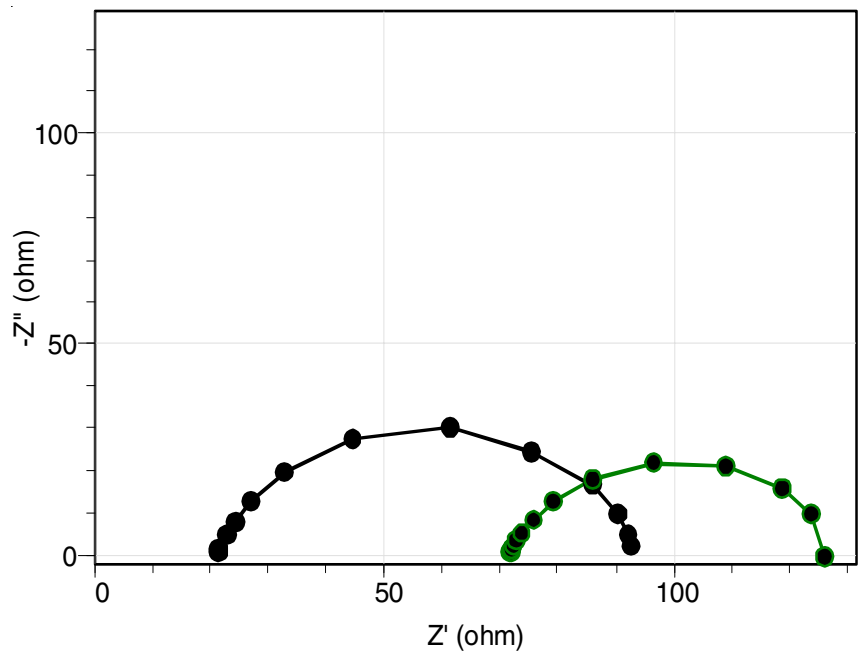

Fig. 3. Nyquist plot in absence and presence of G. serrata

Potentiodynamic polarization: The potentiodynamic parameters was calculated from the potentiodynamic polari- zation curves which shows on the addition of $G$. serrata decreases the corrosion current density $\left(\mathrm{I}_{\text {corr }}\right)$. The addition of $G$. serrata shift the $\mathrm{E}_{\text {corr }}$ value, which suggest the reaction is anodic controlled. Anyhow the maximum shift is only $32 \mathrm{mV}$, which may behave as a mixed type inhibitor (Table-3). The addition of $G$. serrata reduces the anodic dissolution of metal and retards the cathodic evolution reaction (Fig. 4).

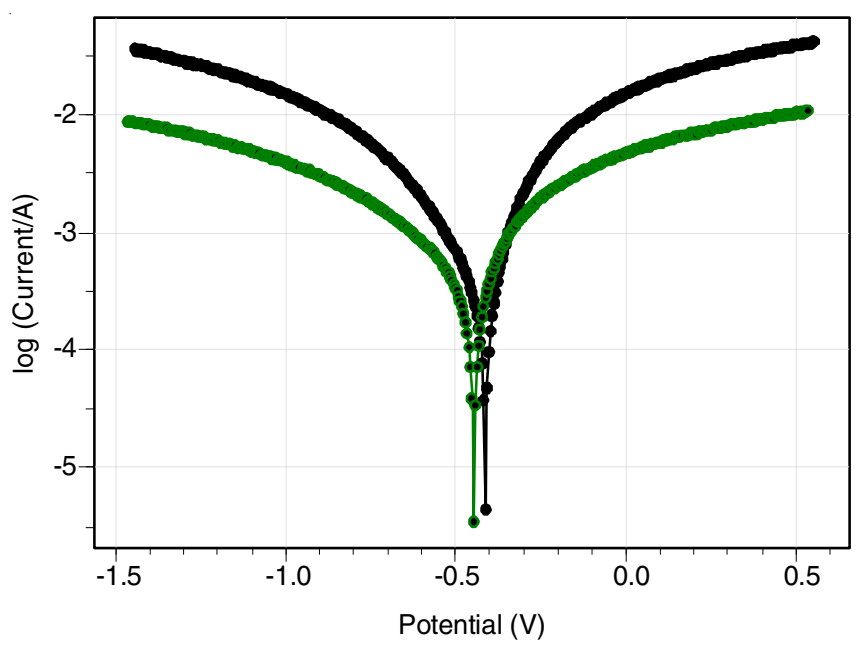

Fig. 4. Tafel polarization curves of G. serrata

\section{Morphological investigation}

SEM analysis: The surface analysis of the specimen establish the interaction of inhibitor molecules with metal surface. SEM images (Fig. 5) revealed that mild steel specimen dipped in $0.5 \mathrm{M} \mathrm{HCl}$ for $3 \mathrm{~h}$ have lot of pits and cavities and the specimen in presence of G. serrata have smoothened surface, where the active phytochemicals are adsorbed on the metal specimen which retards the corrosion rate [19].

FTIR analysis: The FTIR spectra have been used to analyze the protective film formed on the metal surface. The FTIR spectrum of $G$. serrata shows a band at 3469.58 and 3431.41 $\mathrm{cm}^{-1}$ may be phenolic-OH stretching frequency and $-\mathrm{NH}$ stretching frequency respectively. The band at $1633.61 \mathrm{~cm}^{-1}$ is due to $\mathrm{C}=\mathrm{O}$ stretching and the bands at $1357.20 \mathrm{~cm}^{-1}$ is due to $\mathrm{O}-\mathrm{H}$ in plane bending vibrations, while the band at $671.11 \mathrm{~cm}^{-1}$ is due to the presence of aromatic ring [20]. The FTIR spectrum of the thin film formed on the surface of the mild steel after immersing the coupon in $0.5 \mathrm{M} \mathrm{HCl}$ containing $700 \mathrm{ppm}$ of G. serrata extract for $3 \mathrm{~h}$. The band appears at $3414.88 \mathrm{~cm}^{-1}$ due to $-\mathrm{OH}$ stretching, the band at $2830.98 \mathrm{~cm}^{-1}$ due to $-\mathrm{CH}$ stretching of methoxy group and the band appear at 1633.61 $\mathrm{cm}^{-1}$ in G. serrata is shifted to $1593.27 \mathrm{~cm}^{-1}$ and the new peaks appear at $1714.56 \mathrm{~cm}^{-1}(\mathrm{C}=\mathrm{O}), 1363.51 \mathrm{~cm}^{-1}(\mathrm{C}-\mathrm{N})$ and 1222.97 $\mathrm{cm}^{-1}(\mathrm{C}-\mathrm{O})$ are due to amide stretching frequencies [21].

Based on the above characterizations the G. serrata was proved to be an efficient inhibitor and this was further confirmed by comparing the G. serrata with other inhibitors and tabulated in Table- 4 .

TABLE-3

POTENTIODYNAMIC POLARIZATION AND LINEAR POLARIZATION PARAMETERS OF G. serrata

\begin{tabular}{|c|c|c|c|c|c|}
\hline System & $\mathrm{E}_{\text {corr }}(\mathrm{mV} / \mathrm{SCE})$ & $\mathrm{I}_{\text {corr }}\left(\mu \mathrm{A} \mathrm{cm}^{-2}\right)$ & $\beta_{\mathrm{a}}(\mathrm{mV} / \mathrm{dec})$ & $\beta_{\mathrm{c}}(\mathrm{mV} / \mathrm{dec})$ & $\mathrm{R}_{\mathrm{p}}$ \\
\hline Blank & -416.4 & 369 & 943 & 750 & 110.1 \\
\hline Inhibitor & -448.0 & 161 & 1139 & 930 & 134.0 \\
\hline
\end{tabular}



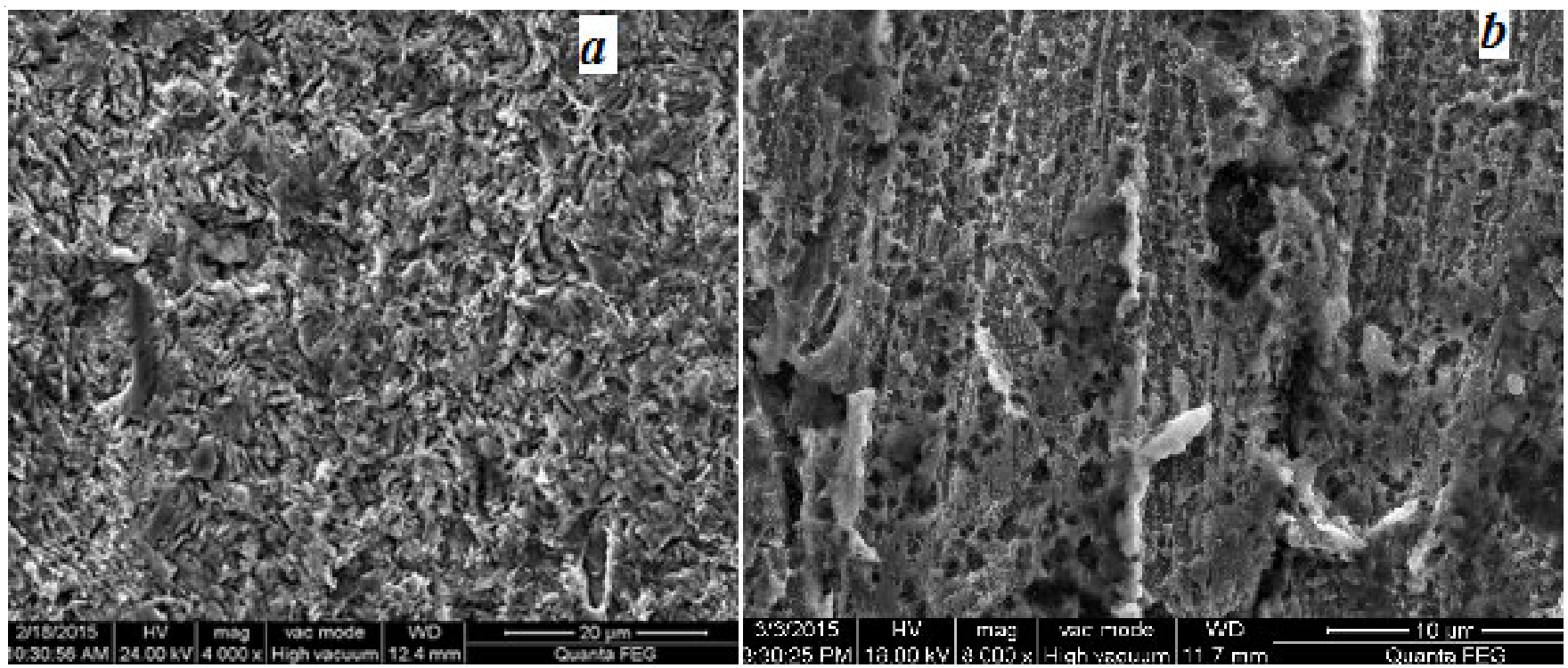

Fig. 5. SEM micrograph of (a) mild steel immersed in $0.5 \mathrm{M} \mathrm{HCl} \mathrm{(b)} \mathrm{mild} \mathrm{steel} \mathrm{immersed} \mathrm{in} \mathrm{the} \mathrm{presence} \mathrm{of} \mathrm{G.} \mathrm{serrata} \mathrm{in} 0.5 \mathrm{M} \mathrm{HCl}$

\begin{tabular}{|c|c|c|c|c|}
\hline \multicolumn{5}{|c|}{$\begin{array}{c}\text { TABLE-4 } \\
\left.\text { CORROSION CURRENT DENSITY ( } \mathrm{I}_{\text {corr }}\right) \text { AND CHARGE TRANSFER RESISTANCE }\left(\mathrm{R}_{\mathrm{c}}\right) \text { OF G. serrata } \\
\text { IN } 0.5 \mathrm{M} \text { HCl MEDIUM FOR MILD STEEL IS COMPARED WITH OTHER EXTRACTS }\end{array}$} \\
\hline Plant extract & Concentration & $\begin{array}{l}\text { Corrosion current } \\
\text { density }\left(\mathrm{I}_{\text {corr }}, \mathrm{A} \mathrm{cm}^{-2}\right)\end{array}$ & $\begin{array}{c}\text { Charge transfer } \\
\text { resistance }\left(\mathrm{R}_{\mathrm{c}}, \Omega \mathrm{cm}^{2}\right)\end{array}$ & Ref. \\
\hline Gomphrena serrata leaves & $700 \mathrm{ppm}$ & $161.0 \times 10^{-6}$ & 493.0 & This work \\
\hline Cissus quadrangularis leaves & $200 \mathrm{ppm}$ & $2.768 \times 10^{-4}$ & 56.0 & [22] \\
\hline Ziziphus mauritiana leaves & $2800 \mathrm{ppm}$ & $0.613 \times 10^{-3}$ & 163.3 & {$[23]$} \\
\hline Lycium shawii & $0.01 \mathrm{~g} / 100 \mathrm{~mL}$ & $0.680 \times 10^{-3}$ & 73.6 & [24] \\
\hline Teucrium oliverianum & $0.01 \mathrm{~g} / 100 \mathrm{~mL}$ & $1.230 \times 10^{-3}$ & 73.6 & [24] \\
\hline Ochradenus baccatus & $0.01 \mathrm{~g} / 100 \mathrm{~mL}$ & $0.710 \times 10^{-3}$ & 112.7 & {$[24]$} \\
\hline Anvillea garcinii & $0.01 \mathrm{~g} / 100 \mathrm{~mL}$ & $1.280 \times 10^{-3}$ & 66.6 & [24] \\
\hline Cassia italic & $0.01 \mathrm{~g} / 100 \mathrm{~mL}$ & $1.770 \times 10^{-3}$ & 23.6 & [24] \\
\hline Artemisia sieberi & $0.01 \mathrm{~g} / 100 \mathrm{~mL}$ & $0.420 \times 10^{-3}$ & 62.3 & [24] \\
\hline Carthamus tinctorius & $0.01 \mathrm{~g} / 100 \mathrm{~mL}$ & $0.510 \times 10^{-3}$ & 46.1 & [24] \\
\hline Tripleurospermum auriculatum & $0.01 \mathrm{~g} / 100 \mathrm{~mL}$ & $1.420 \times 10^{-3}$ & 62.0 & {$[24]$} \\
\hline
\end{tabular}

\section{Synthesis of copper nanoparticles using $G$. serrata}

Visual observation: The visual observation of sea green colour confirms the formation of $G$. serrata mediated copper nanoparticles. Initially the extract was yellow in colour, after $1 \mathrm{~h}$ at room temperature and $5 \mathrm{~min}$ in microwave method the colour formation confirms the formation of copper nanoparticles [25].

Effect of thermostat and microwave method: Temperature plays a vital role on the blend of nanoparticles where the G. serrata was used as a reductant. The colour changes occurs in $1 \mathrm{mM}$ within $5 \mathrm{~min}$ in microwave oven but in thermostat method $3 \mathrm{mM} \mathrm{CuSO}_{4}$ was favourable for the formation of copper nanoparticles it takes $1 \mathrm{~h}$. The optimization study shows a significant effect on the synthesis of copper nanoparticles and the higher centralization of metal arrangement recommends the total of nanoparticles [26]. The development of copper nanoparticles increases with in temperature by utilizing the leaf concentrate of $G$. seratta. The absorbance band was expanded and situated at $341 \mathrm{~nm}$ and $345 \mathrm{~nm}$ at thermostat and microwave technique, separately (Fig. 6). At high temperature the decrease was supported because of the utilization of copper particle in the arrangement of cores. Finally, it was concluded that the optimum temperature was depend on the methods we adopt for the synthesis of nanoparticles [27].

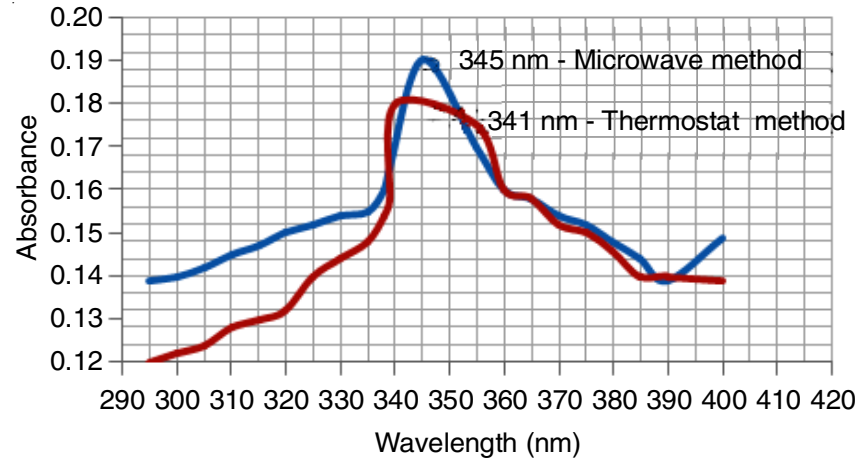

Fig. 6. UV-visible spectra of $G$. serrata mediated CuNPs

FTIR analysis: The functional group analysis was carried out using FTIR the band appear at $3431.41 \mathrm{~cm}^{-1}$ present in $G$. serrata shifted to $3329.14 \mathrm{~cm}^{-1}$ confirms the presence of phenolic-OH group, the band at $1633.61 \mathrm{~cm}^{-1}$ in G. serrata is shifted $1637.56 \mathrm{~cm}^{-1}$ confirms the presence of $\mathrm{C}=\mathrm{O}$ group and the band at $671.11 \mathrm{~cm}^{-1}$ present in G. serrata is shifted to $640.37 \mathrm{~cm}^{-1}$ confirms the presence of aromatic ring. An analysis of the FTIR spectra of the extract and the synthesized CuNPs revealed that the copper nanoparticles might be surrounded by molecules like polyphenols, reducing sugars 
and flavonoids, which are commonly found in plant extracts. These chemical constituents present in the leaf extract are capable of converting copper sulphate to copper nanoparticles due to their capping and reducing capacities. From these observations it is clear that the phytochemicals present in $G$. serrata leaf extract are responsible for reduction and stabilization by capping of CuNPs.

\section{Conclusion}

The present study revealed that the potential efficiency of $G$. serrata was an efficient corrosion inhibitor as well as an efficient reductant. The $G$. serrata acts as anodic type inhibitor, which retards active passage of corrosion by forming a thin film formed on the surface which was confirmed through surface analysis. The G. serrata was also served as an efficient reducing agent for the synthesis of copper nanoparticles. Two methods were adopted for the synthesis, in that microwave method is preferred due to its time consuming and easiness. The $G$. serrata was used as a reducing as well as a stabilizing agent, which was confirmed through FTIR analysis.

\section{CONFLICT OF INTEREST}

The authors declare that there is no conflict of interests regarding the publication of this article.

\section{REFERENCES}

1. C. Vieira, H. Mercier, E. Chu and R.C.L. Figueiredo-Ribeiro, ed.: Y.P.S. Bajaj, Gomphrena species (globe Amaranth): In vitro Culture and Production of Secondary Metabolites, In: Biotechnology in Agriculture and Forestry, Springer-Verlag: Berlin, pp. 257-270 (1994).

2. A.M. Rahman and M.I.A. Gulshana, Appl. Ecol. Environ. Sci., 2, 54 (2014).

3. M. Benabdellah, B. Hammouti, A. Warthan, S.S. Al-Deya, C. Jama, M. Lagrenee and F. Bentiss, Int. J. Electrochem. Sci., 7, 3489 (2012).

4. X.J. Raj and N. Rajendran, J. Mater. Eng. Perform., 21, 1363 (2012); https://doi.org/10.1007/s11665-011-0007-0.

5. D. Seifzadeh, H. Basharnavaz and A. Bezaatpour, Mater. Chem. Phys., 138, 794 (2013);

https://doi.org/10.1016/j.matchemphys.2012.12.063.

6. M.A. Quraishi and D. Jamal, Mater. Chem. Phys., 71, 202 (2001); https://doi.org/10.1016/S0254-0584(00)00378-3.
7. N. Soltani, N. Tavakkoli, M. Khayatkashani, M.R. Jalali and A. Mosavizade, Corros. Sci., 62, 122 (2012); https://doi.org/10.1016/j.corsci.2012.05.003.

8. P.B. Raja, A.K. Qureshi, A. Abdul-Rahim, H. Osman and K. Awang, Corros. Sci., 69, 292 (2013); https://doi.org/10.1016/j.corsci.2012.11.042.

9. O.K. Abiola and J.O.E. Otaigbe, Corros. Sci., 51, 2790 (2009); https://doi.org/10.1016/j.corsci.2009.07.006

10. G. Borkow, J. Gabbay, R. Dardik, A.I. Eidelman, Y. Lavie, Y. Grunfeld, S. Ikher, M. Huszar, R.C. Zatcoff and M. Marikovsky, Wound Repair Regen., 18, 266 (2010); https://doi.org/10.1111/j.1524-475X.2010.00573.x.

11. V.C. Kalia and R.S. Lal, J. Sci. Ind. Res., 61, 630 (2002).

12. A. Harborne, Phytochemical Methods a Guide to Modern Techniques of Plant Analysis, Springer (1998).

13. S. Martinez and I. Stern, Appl. Surf. Sci., 199, 83 (2002); https://doi.org/10.1016/S0169-4332(02)00546-9.

14. P. Li, J.Y. Lin, K.L. Tan and J.Y. Lee, Electrochim. Acta, 42, 605 (1997); https://doi.org/10.1016/S0013-4686(96)00205-8.

15. B.M. Praveen and T.V. Venkatesha, Int. J. Electrochem. Sci., 4, 267 (2009).

16. G.N. Mu, X. Li and F. Li, Mater. Chem. Phys., 86, 59 (2004); https://doi.org/10.1016/j.matchemphys.2004.01.041.

17. F. Bentiss, M. Lebrini and M. Lagrenée, Corros. Sci., 47, 2915 (2005); https://doi.org/10.1016/j.corsci.2005.05.034.

18. M.A. Quraishi and J. Rawat, Mater. Chem. Phys., 70, 95 (2001); https://doi.org/10.1016/S0254-0584(00)00459-4.

19. J Buchweishaija, Tanz. J. Sci., 35, 77 (2009).

20. R.A. Kumar and M. Ramasamy, Int. J. Curr. Microbiol. Appl. Sci., 3, 395 (2014).

21. J. Mohan, Organic Spectroscopy-Principles and Applications, Narosa Publishing House: Delhi, edn 2 (2004).

22. E. Dharmaraj, C. Pragathiswaran, P. Govindhan, P.A. Sahayaraj, A.J. Amalraj and V. Dharmalingam, Int. J. Res. Pharm. Chem., 7, 126 (2017).

23. S.S. Shivakumar and K.N.S. Mohana, Eur. J. Chem., 3, 426 (2012); https://doi.org/10.5155/eurjchem.3.4.426-432.671.

24. M.S. Al-Otaibi, A.M. Al-Mayouf, M. Khan, A.A. Mousa, S.A. AlMazroa and H.Z. Alkhathlan, Arab. J. Chem., 7, 340 (2014); https://doi.org/10.1016/j.arabjc.2012.01.015.

25. M. Gopinath, R. Subbaiya, M.M. Selvam and D. Suresh, Int. J. Curr. Microbiol. Appl. Sci., 3, 814 (2014).

26. H. Bar, D.H. Bhui, P.G. Sahoo, P. Sarkar, P.S. De and A. Misra, Colloids Surf. A Physicochem. Eng. Asp., 339, 134 (2009); https://doi.org/10.1016/j.colsurfa.2009.02.008.

27. M. Vanaja, S. Rajeshkumar, K. Paulkumar, G. Gnanajobitha, C. Malarkodi and G. Annadurai, Adv. Appl. Sci. Res., 4, 50 (2013). 